“ (C) 2011 IEEE. Personal use of this material is permitted. Permission from IEEE must be obtained for all other uses, in any current or future media, including

reprinting/republishing this material for advertising or promotional purposes, creating new collective works, for resale or redistribution to servers or lists, or reuse of any copyrighted component of this work in other works." 


\title{
Predictive Direct Torque and Flux Control of Doubly Fed Induction Generator With Switching Frequency Reduction for Wind Energy Applications
}

\author{
Yongchang Zhang*†, Zhengxi $\mathrm{Li}^{*}$, Tianshi Wang ${ }^{\dagger}$, Jiefeng $\mathrm{Hu}^{\dagger}$, Jianguo Zhu ${ }^{\dagger}$ \\ *Inverter Technologies Engineering Research Center of Beijing, North China University of Technology, Beijing, China \\ ${ }^{\dagger}$ Faculty of Engineering and Information Technology, University of Technology Sydney, NSW 2007, Australia \\ Email: yozhang@ieee.org
}

\begin{abstract}
A model based predictive torque and flux control (PTFC) is proposed in this paper for doubly fed induction generator (DFIG) applied in wind energy applications. Different from the conventional switching-table-based direct torque control (DTC), which selects the output vector from a switching table, the developed PTFC selects the most suitable vector minimizing the errors of rotor flux and torque based on predictions of their evolutions versus time. Compared to DTC with the same sampling frequency, there are significant reductions in both torque and flux ripples for PTFC with lower switching frequency, while their dynamic performances are similar. Furthermore, by incorporating the frequency reduction in PTFC, the average switching frequency can be reduced up to $38.76 \%$ without affecting its performance. The results of PTFC operating at a very low switching frequency of below $550 \mathrm{~Hz}$ are presented, validating the capability of PTFC to satisfy the low switching frequency requirement of high power wind energy applications. Simulation results are presented to validate the effectiveness of the proposed PTFC.
\end{abstract}

\section{INTRODUCTION}

Wind energy is growing rapidly over the past 20 years and has become the fastest developing renewable energy resource around the world due to its cleanness and reliability [1] [2]. Among various configurations of wind turbine generators, variable speed wind turbine system based on doubly fed induction generator (DFIG) is the very popular configuration [3]. Conventionally the vector control (VC) strategy is used for DFIG to achieve high performance torque and flux control as well as active and reactive power control by decomposing the rotor current into d-axis and q-axis components. The specific implementations may include stator flux orientation [4] or stator voltage orientation [5]. Although excellent performance is obtained by $\mathrm{VC}$, it relies much on the machine parameters accuracy, and what's more, requires much tuning effort to ensure the system stability and adequate response over the whole operating range [6].

Another scheme to achieve high performance torque control is the so-called direct torque control (DTC), which was proposed in the mid 1980s [7], [8] and was reported to have less parameter dependence and tuning requirement than $\mathrm{VC}$ and very quick response. In conventional DTC, two hysteresis comparators are used to regulate the torque and flux directly by selecting an appropriate voltage vector from a predefined switching table according to the position and stator flux. Due to its simplicity and robustness, DTC has been extended from squirrel cage induction machine to other types of machines, including permanent magnet synchronous machine [9] and doubly fed induction machine [10]. The DTC drive based on multilevel inverter has also been studied in [11]. However, there are some drawbacks of conventional switching-tablebased DTC (DTC) and the two most notable drawbacks are large torque ripple and variable switching frequency.

To improve the steady state performance and fix the switching frequency of DTC, many methods have been proposed in the literature, among which DTC with space vector modulation (DTC-SVM) is a common approach [12], [13]. Although better steady state performance is obtained, DTC-SVM usually requires complicated calculations, more machine parameters and increased tuning effort.

Recently predictive control methods attracted more and more attention and have been proposed to be applied in the area of power electronics converters and electric drives [3], [14]-[17]. In DTC-SVM, the power converter plus modulation is considered as a gain in the controller design, while in predictive control methods the discrete nature of power converters is taken into account by considering the converter and the load from a system view. There are various versions of predictive control, differing in the principle of vector selection and the number of applied vectors [18]. In this paper, the so called finite control set model predictive control (FCSMPC) selecting only one vector based on evaluating a cost function for each voltage vector [16], will be adapted to the control of DFIG for wind energy applications.

Although model predictive control using only one vector has been applied in induction motor drives [17], so far it has not been extended to the doubly fed induction generator (DFIG) for wind energy applications. Furthermore, the switching frequency reduction is not considered in [17]. For high power wind turbine generators, the switching frequency should be kept very low for the sake of efficiency [19]. This paper presents a novel method to reduce the switching frequency while maintaining the torque and flux performances of DFIG by predicting their evolutions over the next several periods. The model based predictive torque and flux control (PTFC) is compared with the DTC and exhibits better performance in terms of steady response and average switching frequency. 
Operation of DFIG with very low switching frequency of no more than $550 \mathrm{~Hz}$ is also shown to verify the effectiveness of the PTFC for high power wind energy applications. Simulation results are presented to confirm the superiority of the developed predictive method in this paper.

\section{MAChine EQUATIONS OF DFIG}

The model of DFIG in rotor frame is expressed as:

$$
\begin{aligned}
\boldsymbol{u}_{s} & =R_{s} \boldsymbol{i}_{s}+\frac{d \boldsymbol{\psi}_{s}}{d t}+j \omega_{r} \boldsymbol{\psi}_{s} \\
\boldsymbol{u}_{r} & =R_{r} \boldsymbol{i}_{r}+\frac{d \boldsymbol{\psi}_{r}}{d t} \\
\boldsymbol{\psi}_{s} & =L_{s} \boldsymbol{i}_{s}+L_{m} \boldsymbol{i}_{r} \\
\boldsymbol{\psi}_{r} & =L_{m} \boldsymbol{i}_{s}+L_{r} \boldsymbol{i}_{r} \\
T_{e} & =\frac{3}{2} p \lambda L_{m}\left(\boldsymbol{\psi}_{r} \otimes \boldsymbol{\psi}_{s}\right)
\end{aligned}
$$

where $\boldsymbol{u}_{\boldsymbol{s}}, \boldsymbol{i}_{s}, \boldsymbol{u}_{r}, \boldsymbol{i}_{r}, \boldsymbol{\psi}_{s}$ and $\boldsymbol{\psi}_{r}$ are the stator voltage vector, stator current vector, rotor voltage vector, rotor current vector, stator flux linkage vector and rotor flux linkage vector, respectively; $R_{s}, R_{r}, L_{s}, L_{r}$ and $L_{m}$ are the stator resistance, rotor resistance, stator inductance, rotor inductance and mutual inductance, respectively; $\omega_{r}$ and $p$ are the electrical rotor speed and pole pairs and $\lambda=1 /\left(L_{s} L_{r}-L_{m}^{2}\right)$.

From (1) to (4), the model of DFIG can be expressed in the form of state space equations (with $\psi_{s}$ and $\psi_{r}$ as state variables) as:

$$
\begin{aligned}
\frac{d \boldsymbol{\psi}_{s}}{d t} & =-\left(\lambda L_{r} R_{s}+j \omega_{r}\right) \boldsymbol{\psi}_{s}+\lambda L_{m} R_{s} \boldsymbol{\psi}_{r}+\boldsymbol{u}_{s} \\
\frac{d \boldsymbol{\psi}_{r}}{d t} & =\lambda L_{m} R_{r} \boldsymbol{\psi}_{s}-\lambda L_{s} R_{r} \boldsymbol{\psi}_{r}+\boldsymbol{u}_{r}
\end{aligned}
$$

\section{Model Based Predictive Torque And Flux CONTROL}

\section{A. Basic Principle}

The PTFC is similar to DTC only in that they both select one and only one voltage vector, but the basic principle in selecting voltage vector is very different. The DTC uses a heuristic switching table to obtain the vector, which is determined when the difference between preferences and estimations occurs. On the contrary, the PTFC predicts the evolutions of torque and flux over the next several periods for each possible voltage vector, and then selects the one minimizing the errors between the references and estimations. As a result, better performance can be anticipated for PTFC. It can be said that the voltage vector obtained from PTFC is more accurate and effective in controlling the torque and rotor flux than its counterpart obtained from DTC.

The key technology of PTFC lies in the definition of cost function, which is usually related to the control objectives. For DFIG used in wind energy applications, the torque (corresponding to active power) and rotor flux (corresponding to reactive power) are of concern. The cost function will be defined in such a way that both torque and rotor flux at the end

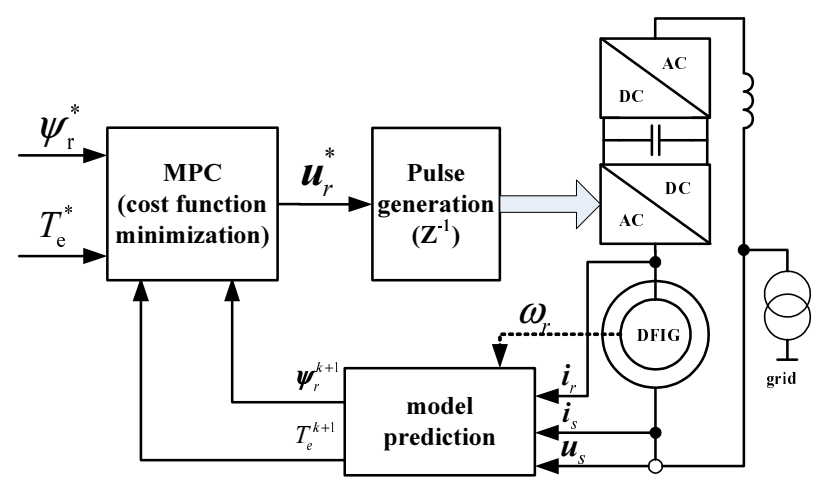

Fig. 1. Control diagram of PTFC for DFIG

of the control period is as close as possible to the commanding value. Specifically, the cost function is defined as:

$$
\begin{aligned}
\min . & g=\left|T_{e}^{*}-T_{e}^{k+1}\right|+k_{1}|| \boldsymbol{\psi}_{r}^{*}|-| \boldsymbol{\psi}_{r}^{k+1}|| \\
\text { s.t. } & \boldsymbol{u}_{r}^{k} \in\left\{\mathbf{V}_{0}, \mathbf{V}_{1}, \ldots \mathbf{V}_{6}, \mathbf{V}_{7}\right\}
\end{aligned}
$$

where $k_{1}$ is the weighting factor. The selection of $k_{1}$ is still an open problem for answer [16]. In this paper, $k_{1}$ is selected to be $T_{n} / \psi_{n}$ to give torque and flux the same weight, where $T_{n}$ and $\psi_{n}$ are the rated value for torque and stator flux, respectively. It should be noted that when a null vector is selected, the specific state $\left(\mathbf{V}_{0}\right.$ or $\left.\mathbf{V}_{7}\right)$ will be determined on the principle of minimal switching commutations, which is related to the switching states of the old voltage vector.

The torque and rotor flux at $(k+1) t h$ instant can be obtained by discretizing the equations (6) and (7) as:

$\boldsymbol{\psi}_{s}^{k+1}=\boldsymbol{\psi}_{s}^{k}+T_{s}\left[-\left(\lambda L_{r} R_{s}+j \omega_{r}^{k}\right) \boldsymbol{\psi}_{s}^{k}+\lambda L_{m} R_{s} \boldsymbol{\psi}_{r}^{k}+\boldsymbol{u}_{s}^{k}\right]$

$\boldsymbol{\psi}_{r}^{k+1}=\boldsymbol{\psi}_{r}^{k}+T_{s}\left[\lambda L_{m} R_{r} \boldsymbol{\psi}_{s}^{k}-\lambda L_{s} R_{r} \boldsymbol{\psi}_{r}^{k}+\boldsymbol{u}_{r}^{k}\right]$

$T_{e}^{k+1}=\frac{3}{2} p \lambda L_{m}\left(\boldsymbol{\psi}_{r}^{k+1} \otimes \boldsymbol{\psi}_{s}^{k+1}\right)$

where $T_{s}$ is the control period. The stator and rotor flux at $k t h$ instant can be easily obtained from the stator and rotor current using (3) and (4).

The whole diagram of the PTFC in this paper is illustrated in Fig. 1.

\section{B. Delay Compensation}

The cost function in (8) assumes that all calculations and judgments are implemented in the kth instant and the selected vector will be applied immediately. However, in practical digital implementation, this assumption is not true and the applied voltage vector is not applied until the $(k+1) t h$ instant. In other word, for the duration between $k t h$ and $(k+1) t h$ instants, the applied rotor voltage vector $\boldsymbol{u}_{r}^{k}$ has been decided by the value in the $(k-1) t h$ instant and the evolutions of $\psi_{r}$ and $T_{e}$ for this duration are uncontrollable. What is left to be decided is actually the rotor voltage vector $\boldsymbol{u}_{r}^{k+1}$, which is applied at the beginning of the $(k+1) t h$ instant. To eliminate this one step delay, the variables of $\boldsymbol{\psi}_{r}^{k+2}$ and $T_{e}^{k+2}$ should be used rather than $\psi_{r}^{k+1}$ and $T_{e}^{k+1}$ for the evaluation of the 


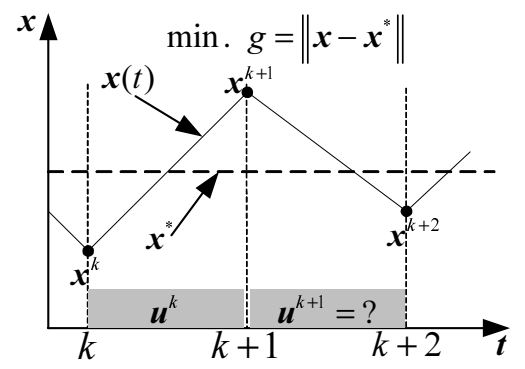

Fig. 2. One-step delay in digital control system

cost function in (8). This fact is clearly illustrated in Fig. 2, where $\boldsymbol{x}$ indicates the state variables of a dynamic system and $\boldsymbol{u}$ is the input to be decided. For PTFC of DFIG, $\boldsymbol{x}$ represents torque and rotor flux and $\boldsymbol{u}$ is the rotor voltage vector.

To eliminate the one-step delay in digital implementation, the cost function in (8) should be changed to (12) as shown below:

$$
\begin{aligned}
\text { min. } & g=\left|T_{e}^{*}-T_{e}^{k+2}\right|+k_{1}|| \boldsymbol{\psi}_{r}^{*}|-| \boldsymbol{\psi}_{r}^{k+2}|| \\
\text { s.t. } & \boldsymbol{u}_{r}^{k+1} \in\left\{\mathbf{V}_{0}, \mathbf{V}_{1}, \ldots \mathbf{V}_{6}, \mathbf{V}_{7}\right\}
\end{aligned}
$$

Obtaining $T_{e}^{k+2}$ and $\boldsymbol{\psi}_{r}^{k+2}$ in (12) requires a two-step prediction. The variables at the $(k+1) t h$ instant have been obtained using (9)-(11), where $\boldsymbol{u}_{r}^{k}$ is a known variable. To obtain the best rotor voltage vector minimizing the cost function in (12), each possible configuration for $\boldsymbol{u}_{r}^{k+1}$ will be evaluated to obtain the value at $(k+2) t h$ instant. The predictive model is the same as in (9)-(11) except that the variables in the right side are replaced by the value at $(k+1) t h$ instant.

\section{Switching Frequency Reduction}

The PTFC is very flexible in incorporating any nonlinear constraints which are usually difficult to consider in the linear controllers. This paper will impose the switching frequency reduction in the PTFC while keeping the torque and flux performances. The prior paper regarding motor drives [17] failed to consider this aspect and the switching frequency reduction is only considered in few power converter control, such as the current control of neutral-point-clamped inverter in [14]. Furthermore, the proposed method addressing frequency reduction in this paper is different from that in [14] by considering the evolutions of errors over a relative long relative horizon.

The proposed cost function considering switching frequency reduction is expressed as

$$
\begin{aligned}
& \text { min. } g=\left|T_{e}^{*}-T_{e}^{k+2}\right|+k_{1}|| \boldsymbol{\psi}_{r}^{*}|-| \boldsymbol{\psi}_{r}^{k+2}|| \\
&+A\left(\left|T_{e}^{*}-T_{e}^{k+N}\right|+k_{1}|| \boldsymbol{\psi}_{r}^{*}|-| \boldsymbol{\psi}_{r}^{k+2}||\right) \\
&+B\left(\sum_{i=a, b, c}\left|\boldsymbol{u}_{r}^{k+1}\left(S_{i}\right)-\boldsymbol{u}_{r}^{k}\left(S_{i}\right)\right|\right) \\
& \text { s.t. } \quad \boldsymbol{u}_{r}^{k+1} \in\left\{\mathbf{V}_{0}, \mathbf{V}_{1}, \ldots \mathbf{V}_{6}, \mathbf{V}_{7}\right\}
\end{aligned}
$$

TABLE I

Control And Machine Parameters

\begin{tabular}{lcr}
\hline DC-bus voltage [V] & $V_{d c}$ & 500 \\
Rated motor power [kW] & $P_{N}$ & 15 \\
Rated motor voltage [V] & $U_{N}$ & 380 \\
Rated (Based) motor frequency [Hz] & $f_{N}$ & 50 \\
Number of motor pairs & $N_{p}$ & 2 \\
Motor stator resistance $[\Omega]$ & $R_{s}$ & 0.168 \\
Motor rotor resistance $[\Omega]$ & $R_{r}$ & 0.199 \\
Motor mutual inductance $[\mathrm{H}]$ & $L_{m}$ & 0.050 \\
Motor stator inductance $[\mathrm{H}]$ & $L_{s}$ & 0.050 \\
Motor rotor inductance $[\mathrm{H}]$ & $L_{r}$ & 0.045 \\
\hline
\end{tabular}

There are three items in (13). The first item is the same as in (12); the second one considers the errors in the $(k+N) t h$ instant $(N>1)$ with the weighting factor of $A$; the final item is related to commutation frequency reduction, where $\boldsymbol{u}_{r}^{k}\left(S_{i}\right)$ and $\boldsymbol{u}_{r}^{k+1}\left(S_{i}\right)$ represent the switching state of phase $i(i=$ $a, b, c)$ at the present cycle (during $k t h$ and $(k+1) t h$ instant) and the next cycle (during $(k+1) t h$ and $(k+2) t h$ instant), respectively. For example, if $\boldsymbol{u}_{r}^{k}=\mathbf{V}_{1}(100)$, then $\boldsymbol{u}_{r}^{k}\left(S_{a}\right)=$ $1, \boldsymbol{u}_{r}^{k}\left(S_{b}\right)=0$ and $\boldsymbol{u}_{r}^{k}\left(S_{c}\right)=0$. The weighting factor for commutation frequency reduction is $B$.

The introduction of the second term in (13) is necessary to improve the system stability. If $B$ is too large, i.e. reducing commutation frequency is more of concern, the performance of torque and flux will be deteriorated. Controlling the error at the next $N$ instants will help to stabilize the system when $B$ is too large. Different from the model-based predictions for $T_{e}^{k+2}$ and $\boldsymbol{\psi}_{r}^{k+2}$, the rotor flux and torque at $(k+N) t h$ instant are predicted from the value at $(k+1) t h$ and $(k+2) t h$ instants using linear extrapolations, which are expressed as

$$
\begin{aligned}
T_{e}^{k+N} & =T_{e}^{k+1}+(N-1)\left(T_{e}^{k+2}-T_{e}^{k+1}\right) \\
\left|\boldsymbol{\psi}_{r}^{k+N}\right| & =\left|\boldsymbol{\psi}_{r}^{k+1}\right|+(N-1)\left(\left|\boldsymbol{\psi}_{r}^{k+2}\right|-\left|\boldsymbol{\psi}_{r}^{k+1}\right|\right)
\end{aligned}
$$

Using linear extrapolation for prediction horizon $N$ larger than 2 is reasonably feasible, especially when the sampling period is very short [15].

\section{Simulation Results}

The PTFC is simulated in the environment of Matlab/Simulink for a $15 \mathrm{~kW}$ DFIG. The machine parameters of DFIG is shown in Tab. I [19]. To validate the performance superiority of the proposed PTFC, the results obtained from DTC are also presented. More details regarding DTC for DFIG can be found in [10], which is not repeated here due to the page limitations. The default sampling frequency is $20 \mathrm{kHz}$ for both PTFC and DTC unless explicitly indicated. The hysteresis band width is zero for DTC and the weighting factors in (12) are $k_{1}=100, A=0.1, B=1$ and $N=10$.

\section{A. Performance Comparison Between PTFC and DTC}

Firstly, the performance comparison between PTFC and DTC is carried out, as shown in Figs. 3 and 4. The cost function of PTFC in this test is (12), without considering the switching frequency reduction in (13). The rotor speed is operating at $0.8 \mathrm{pu}$. The torque steps from zero to $-1 \mathrm{pu}$ 

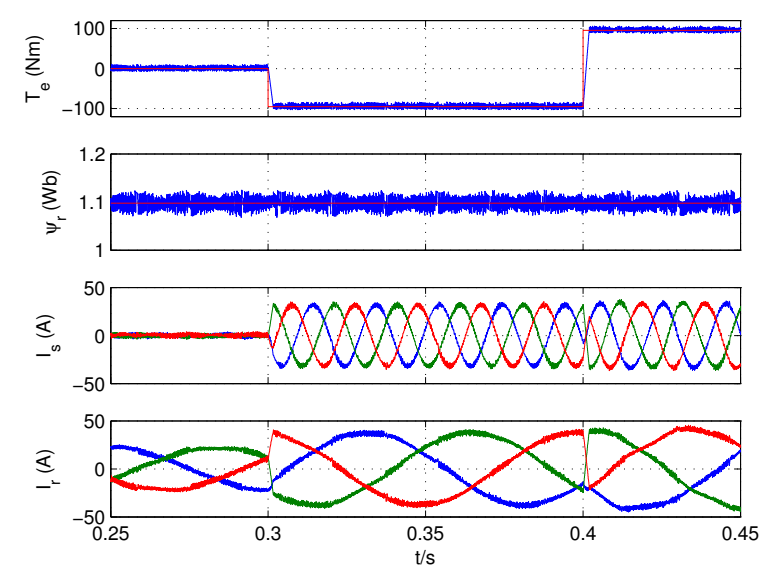

Fig. 3. Responses of torque, rotor flux, stator current and rotor current using DTC $\left(\omega_{m}=0.8 \mathrm{pu}\right)$
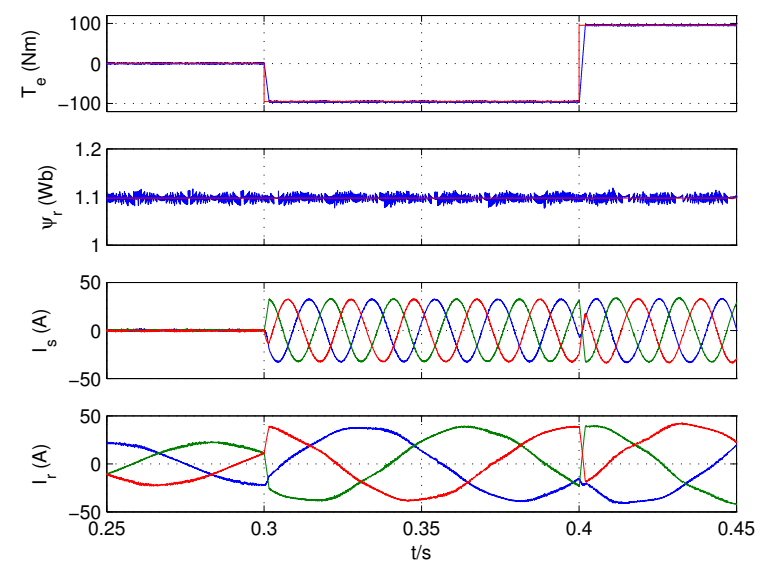

Fig. 4. Responses of torque, rotor flux, stator current and rotor current using $\operatorname{PTFC}\left(\omega_{m}=0.8 \mathrm{pu}\right)$

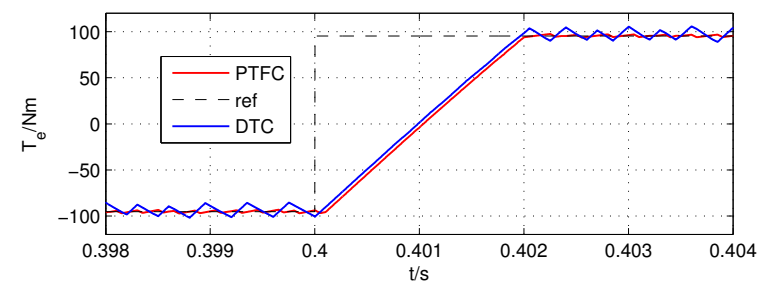

Fig. 5. Zoomed torque responses from -1 pu to 1 pu for PTFC and DTC

(generation) at $\mathrm{t}=0.3 \mathrm{~s}$ and then steps from $-1 \mathrm{pu}$ to $1 \mathrm{pu}$ at $\mathrm{t}=0.4 \mathrm{~s}$ (motoring). The rotor flux is kept constant at 1.0974 $\mathrm{Wb}$. During the transient process, there is absolute absence in the stator and rotor currents. It is clearly seen that the ripples in torque and flux of PTFC is much lower than those of of DTC, while the dynamic performance is similar for them, taking only around 2 milliseconds for them to switch from -1 pu torque to $+1 \mathrm{pu}$, as shown in Fig. 5 .

The harmonic spectra of stator and rotor currents under the steady state condition of $95.4930 \mathrm{Nm}$ and $1.0974 \mathrm{~Wb}$ at $0.8 \mathrm{pu}$ synchronous speed ( $\mathrm{t}>0.4 \mathrm{~s}$ ) for DTC and PTFC are shown in
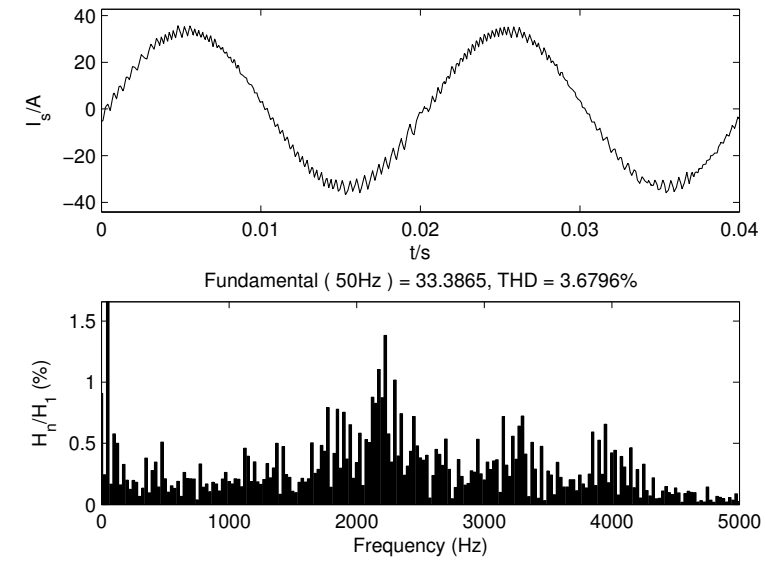

Fig. 6. Harmonic spectrum of stator current using DTC.
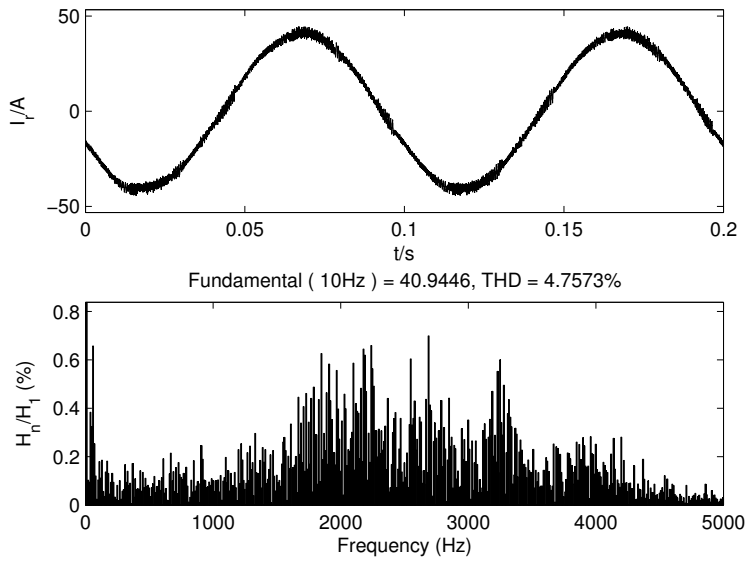

Fig. 7. Harmonic spectrum of rotor current using DTC.
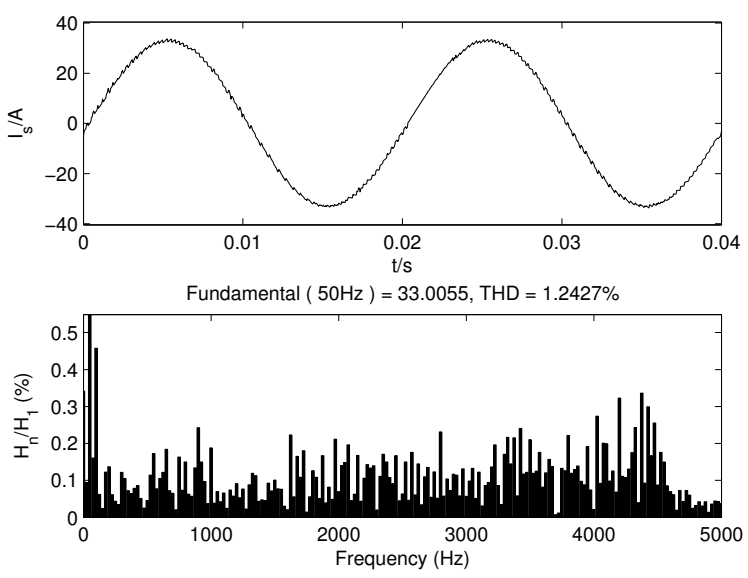

Fig. 8. Harmonic spectrum of stator current using PTFC.

Figs. 6 to 9. It is seen that the THDs of stator and rotor currents for PTFC are much lower than those of DTC, from 3.68\% (DTC) to $1.24 \%$ (PTFC) for stator current and $4.76 \%$ (DTC) to $1.67 \%$ (PTFC) for rotor current. The THD is calculated up to $5000 \mathrm{~Hz}$ harmonics.

Although PTFC has much better performance in terms of 

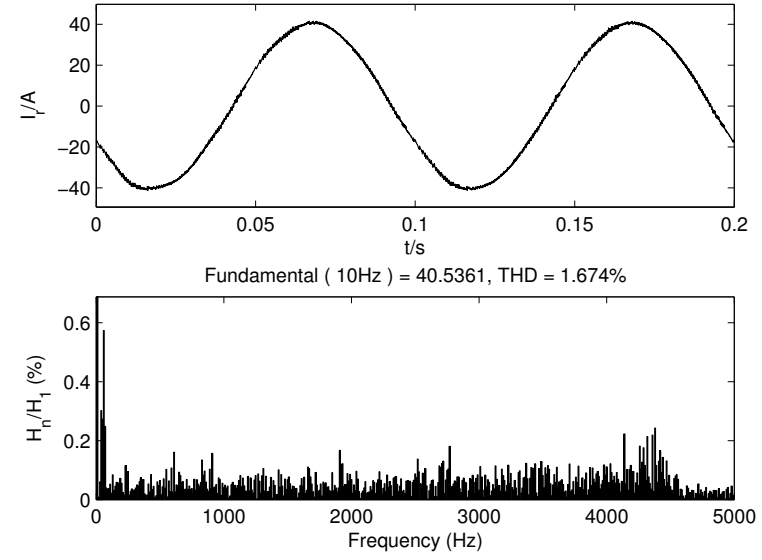

Fig. 9. Harmonic spectrum of rotor current using PTFC.
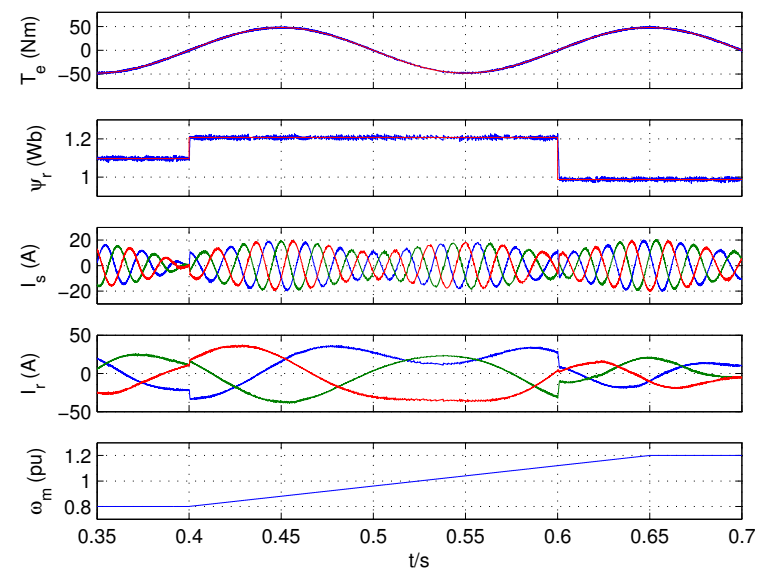

Fig. 10. Tracking behavior of PTFC under the condition of stepped rotor flux reference and sinusoidal torque reference with rotor speed varying from $0.8 \mathrm{pu}$ to $1.2 \mathrm{pu}$

torque and flux ripples and harmonic contents of stator and rotor currents, the average switching frequency of PTFC is even lower than that of DTC, about $2.09 \mathrm{kHz}$ at steady state. The average switching frequency of DTC under the same steady state condition is about $2.94 \mathrm{kHz}$. Based on the results above, it may be said that PTFC is more competitive than DTC in the wind energy applications.

\section{B. Tracking Behavior}

The tracking behavior of PTFC is also tested in this paper. Fig. 10 presents the responses of torque, rotor flux, stator and rotor currents under the condition of stepped rotor flux reference and sinusoidal torque reference when the rotor speed is varying from $0.8 \mathrm{pu}$ to $1.2 \mathrm{pu}$. The results show that the real torque and rotor flux can track their respective reference value closely, even with variable rotor speed, exhibiting excellent tracking performance.

\section{Performance With Switching Frequency Reduction}

The results of PTFC considering the switching frequency reduction in (13) is shown in Fig. 11. The test condition is the
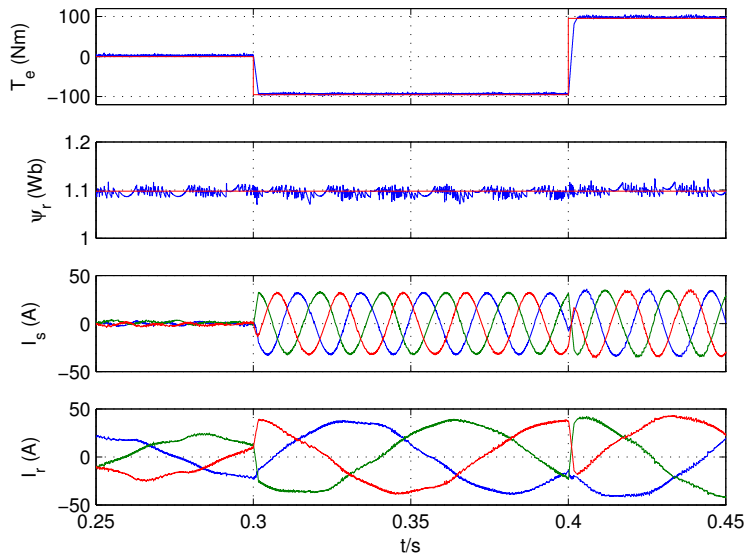

Fig. 11. Responses of torque, rotor flux, stator current and rotor current for PTFC with consideration of switching frequency reduction in (13) $\left(\omega_{m}=0.8\right.$ pu)

same as Fig. 3, except that the cost function is changed from (12) to (13). Compared to the result of $2.09 \mathrm{kHz}$ using (12), there is a significant switching frequency reduction of $38.76 \%$, about $1.28 \mathrm{kHz}$ in this test. At the same time, the performance degradation is very insignificant, as shown in Fig. 11. The THDs of stator and rotor currents are not much increased, from $1.24 \%$ (using (12)) to $1.65 \%$ (using (13)) for stator current and $1.67 \%$ (using (12)) to $2.48 \%$ (using (13)) for rotor current. Due to page limitations, the harmonic spectra of stator and rotor currents are not shown.

\section{Operation With Very Low Switching Frequency}

By using PTFC, the system can operate at a very low switching frequency of a few hundred hertz. Figs. 12 to 14 present the results of PTFC with sampling frequency of 5 $\mathrm{kHz}$. The test condition is the same as that in Fig. 3 and the switching frequency reduction is not considered here. The average switching frequency at steady state $(\mathrm{t}>0.4 \mathrm{~s})$ is about $547 \mathrm{~Hz}$, much lower than the results in Figs. 4 and 11. The THDs of stator and rotor currents are 5.96\% and 6.32\% respectively. Compared to the results with higher switching frequency, the steady state performances of torque and rotor flux are deteriorated, but still at an acceptable level considering the very low switching frequency. The THD of stator current is also lower than the result of $9.9 \%$ at $1 \mathrm{kHz}$ shown in Fig. 9 of [19] using another kind of predictive DTC.

\section{CONCLUSION}

This paper proposes a model based predictive torque and flux control of DFIG and compares it with conventional DTC. It is shown that the PTFC provides much better steady performance, similar dynamic response and lower switching frequency under the condition of the same sampling frequency. One of the merits of the proposed PTFC is its flexibility, such as taking into the switching frequency reduction into account, as shown in this paper. The performance is only slightly affected but the average switching frequency is reduced up to $38.76 \%$ by considering the switching frequency reduction 

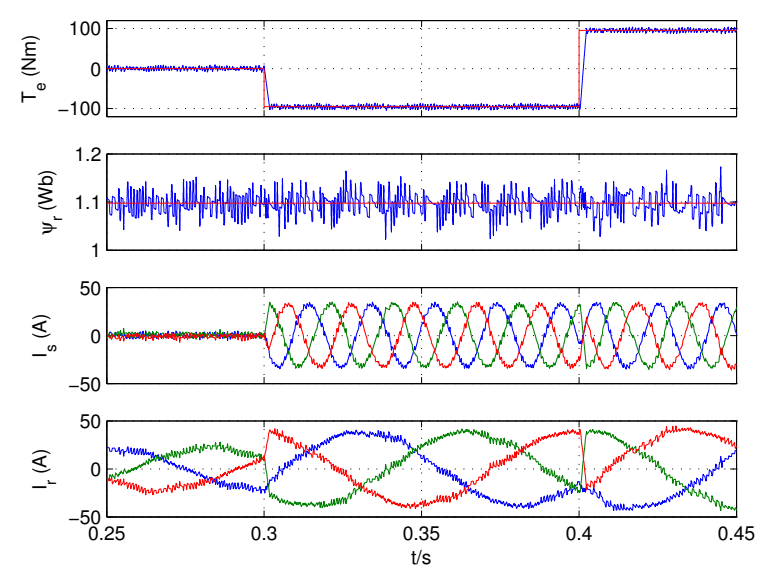

Fig. 12. Responses of torque, rotor flux, stator current and rotor current using PTFC $\left(\omega_{m}=0.8 \mathrm{pu}\right)$ with sampling frequency of $5 \mathrm{kHz}$
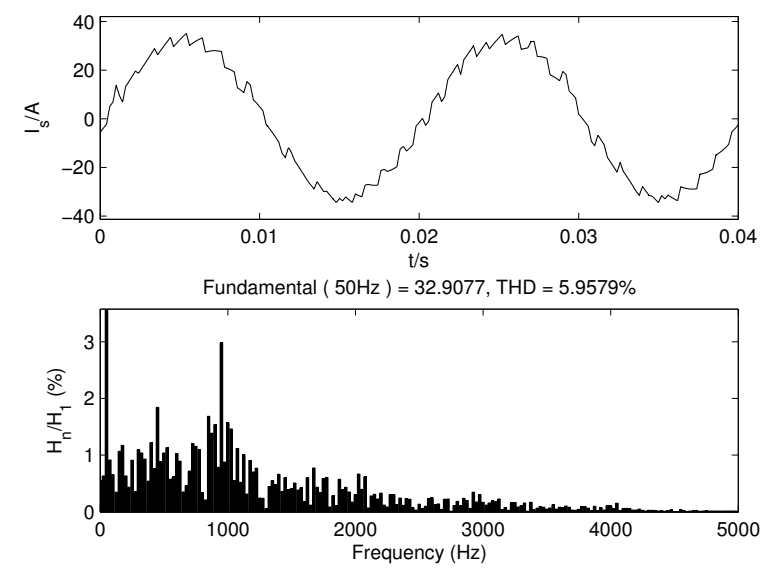

Fig. 13. Harmonic spectrum of stator current for PTFC with sampling frequency of $5 \mathrm{kHz}$
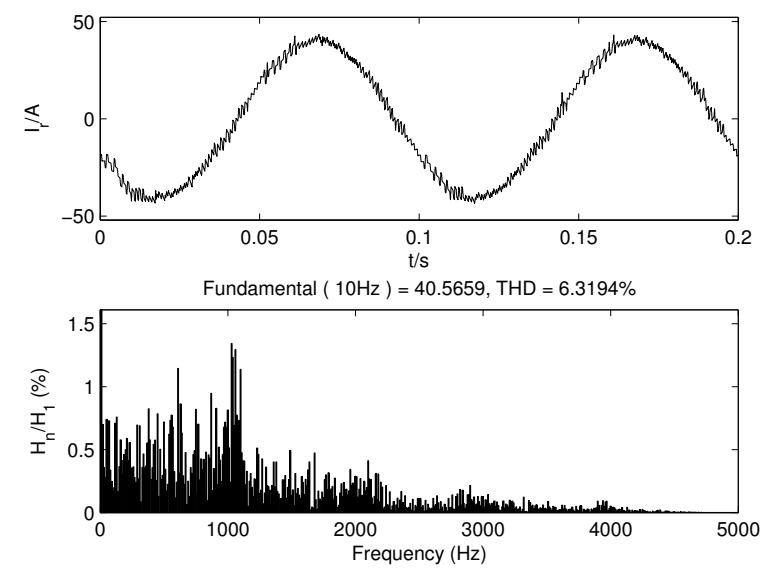

Fig. 14. Harmonic spectrum of rotor current for PTFC with sampling frequency of $5 \mathrm{kHz}$

in the cost function. Furthermore, the PTFC can operate at a very low switching frequency below $550 \mathrm{~Hz}$ with acceptable performance, which makes it very attractive for high power wind energy applications. Simulation results show the effectiveness of the proposed control algorithm.

\section{REFERENCES}

[1] Z. Chen, J. Guerrero, and F. Blaabjerg, "A review of the state of the art of power electronics for wind turbines," IEEE Trans. Power Electron., vol. 24 , no. 8, pp. $1859-1875$, aug. 2009.

[2] H. Li and Z. Chen, "Overview of different wind generator systems and their comparisons," IET Renewable Power Generation, vol. 2, no. 2, pp. $123-138$, june 2008.

[3] Y. Zhang, J. Zhu, and J. Hu, "Model predictive direct torque control for grid synchronization of doubly fed induction generator," in Proc. IEEE Int. Electric Machines and Drives Conf. IEMDC '11, 2011, pp. 775-780.

[4] R. Pena, J. C. Clare, and G. M. Asher, "Doubly fed induction generator using back-to-back pwm converters and its application to variable-speed wind-energy generation," IEE Proceedings -Electric Power Applications, vol. 143, no. 3, pp. 231-241, 1996.

[5] S. Muller, M. Deicke, and R. De Doncker, "Doubly fed induction generator systems for wind turbines," IEEE Ind. Appl. Mag., vol. 8, no. 3, pp. $26-33$, may/jun 2002 .

[6] Y. Zhang and J. Zhu, "Direct torque control of cascaded brushless doubly fed induction generator for wind energy applications," in Proc. IEEE Int. Electric Machines and Drives Conf. IEMDC '11, 2011, pp. 751-756.

[7] M. Depenbrock, "Direct self-control (DSC) of inverter-fed induction machine," IEEE Trans. Power Electron., vol. 3, no. 4, pp. 420-429, Oct. 1988.

[8] I. Takahashi and T. Noguchi, "A new quick-response and high-efficiency control strategy of an induction motor," IEEE Trans. Ind. Appl., vol. IA22, no. 5, pp. 820-827, Sept. 1986.

[9] Y. Zhang and J. Zhu, "Direct torque control of permanent magnet synchronous motor with reduced torque ripple and commutation frequency," IEEE Trans. Power Electron., vol. 26, no. 1, pp. 235 -248, 2011.

[10] S. Arnalte, J. Burgos, and J. Rodriguez-Amenedo, "Direct torque control of a doubly-fed induction generator for variable speed wind turbines," Electric power components and systems, vol. 30, no. 2, pp. 199-216, 2002.

[11] Y. Zhang, J. Zhu, Z. Zhao, W. Xu, and D. G. Drroell, "An improved direct torque control for three-level inverter-fed induction motor sensorless drive," IEEE Trans. Power Electron., vol. 26, pp. 1-12, 2011, in press.

[12] C. Lascu and A. Trzynadlowski, "Combining the principles of sliding mode, direct torque control, and space-vector modulation in a highperformance sensorless ac drive," IEEE Trans. Ind. Appl., vol. 40, no. 1, pp. 170-177, Jan.-Feb. 2004.

[13] Y. Zhang, J. Zhu, W. Xu, and Y. Guo, "A simple method to reduce torque ripple in direct torque-controlled permanent-magnet synchronous motor by using vectors with variable amplitude and angle," IEEE Trans. Ind. Electron., vol. 58, no. 7, pp. 2848-2859, 2011.

[14] R. Vargas, P. Cortes, U. Ammann, J. Rodriguez, and J. Pontt, "Predictive control of a three-phase neutral-point-clamped inverter," IEEE Trans. Ind. Electron., vol. 54, no. 5, pp. 2697 -2705, oct. 2007.

[15] Y. Zhang, J. Zhu, and W. Xu, "Predictive torque control of permanent magnet synchronous motor drive with reduced switching frequency," in Proc. Int Electrical Machines and Systems (ICEMS) Conf, 2010, pp. 798-803.

[16] S. Kouro, P. Cortes, R. Vargas, U. Ammann, and J. Rodriguez, "Model predictive control-a simple and powerful method to control power converters," IEEE Trans. Ind. Electron., vol. 56, no. 6, pp. $1826-1838$ june 2009

[17] H. Miranda, P. Cortes, J. Yuz, and J. Rodriguez, "Predictive torque control of induction machines based on state-space models," IEEE Trans. Ind. Electron., vol. 56, no. 6, pp. 1916 -1924, june 2009.

[18] Y. Zhang and J. Zhu, "A novel duty cycle control strategy to reduce both torque and flux ripples for DTC of permanent magnet synchronous motor drives with switching frequency reduction," IEEE Trans. Power Electron., pp. 1-13, 2011, in press.

[19] G. Abad, M. A. Rodriguez, and J. Poza, "Two-level VSC based predictive direct torque control of the doubly fed induction machine with reduced torque and flux ripples at low constant switching frequency," IEEE Trans. Power Electron., vol. 23, no. 3, pp. 1050-1061, 2008. 